\title{
Correction to: Spirituality and Acknowledgement of Cultural Diversity: Who Said It Is Important?
}

Laura Finn, Rev. Estrella Valino, and Rev. Anthony De Conciliis

\section{Correction to:}

\section{Finn, A. R. Roche Green (eds.), Supportive Care Strategies, Advances and Controversies in Hematopoietic Transplantation and Cell Therapy, https://doi.org/10.1007/978-3-319-59014-1_9}

Owing to an inadvertent error, the name of the co-author of chapter 9 was misspelt as Rev. Estrelle Valino. The name has now been updated rightly to Rev. Estrella Valino. 